\title{
Identificando possibilidades de atuação da Terapia Ocupacional na inclusão escolar
}

\author{
Mariana Graziella Ide, Beatriz Tieko Yamamoto, Carla Cilene Baptista da Silva
}

\begin{abstract}
Resumo: Recentemente, o Terapeuta Ocupacional tem atuado em diferentes contextos educacionais com diversas funções e contribuído para efetivação da educação inclusiva. Ao se considerar que cabe ao Terapeuta Ocupacional não só encaminhar para a escola regular e atender a criança com necessidades educacionais especiais, mas também que há necessidade de um trabalho conjunto entre a Terapia Ocupacional e a comunidade escolar, o presente estudo teve por objetivos identificar e caracterizar as sugestões, dificuldades e necessidades levantadas pelos orientadores educacionais de educação infantil de um município da região da Baixada Santista, relacionadas às intervenções quanto ao processo de inclusão escolar de crianças com necessidades educacionais especiais. Para tanto, participaram deste estudo 15 orientadores educacionais de Unidades Municipais de Educação Infantil, o que correspondeu a $75 \%$ do total. O instrumento de coleta de dados utilizado foi um questionário semiaberto, que possibilitou caracterizar os participantes da pesquisa e identificar sugestões e dificuldades quanto ao processo de inclusão escolar. Os dados obtidos permitiram uma análise qualitativa e quantitativa das dificuldades e dos benefícios das crianças com necessidades educacionais especiais, assim como das dificuldades e sugestões dos profissionais da área da educação quanto ao atual processo de inclusão escolar. Os resultados apresentados neste estudo poderão contribuir para a reflexão sobre as possibilidades de implementação de ações que visem à melhoria da atenção especializada da Terapia Ocupacional à criança no processo de inclusão escolar na perspectiva da educação inclusiva.
\end{abstract}

Palavras-chave: Educação Especial, Terapia Ocupacional, Educação Infantil.

\section{Identifying possible performances of occupational therapy in school inclusion}

\begin{abstract}
Recently, the occupational therapist has been working in different educational contexts with several different functions, contributing for an effective inclusive education. Considering that part of the occupational therapists' responsibilities is not only to assist children with special needs and send them to a regular school, but also to work closely together with schools to make the inclusive education a more natural and acceptable process. The objective of this study was to identify and characterize the suggestions, difficulties and needs related to inclusive education of children with special needs, diagnosed by elementary school counselors in Santos, State of Sao Paulo. In order to complete this study, fifteen elementary school counselors from Santos, which correspond to $75 \%$ of the total, answered a questionnaire with open and closed ended questions on inclusive education in the city. The results of the questionnaire were qualitatively and quantitatively analyzed regarding the difficulties and benefits to children and the difficulties and suggestions of the professionals involved in the current inclusive educational process. The results of this study will contribute to reflection, as well as to the implementation of actions to improve the level of attention given by occupational therapiststo children with special needs on their educational development and inclusive education.
\end{abstract}

Keywords: Education, Special, Occupational Therapy, Early Childhood Education.

Autor para correspondência: Carla Cilene Baptista da Silva, Departamento Saúde, Educação e Sociedade, Universidade Federal de São Paulo UNIFESP, Av. Dona Ana Costa, 95, Vila Mathias, CEP 11060-001, Santos, SP, Brasil

Recebido em 14/12/2010; Revisão em 12/9/2011; Aceito em 19/9/2011. 


\section{Introdução}

Tradicionalmente voltada para a reabilitação, a Terapia Ocupacional vem alterando suas açóes de avanço no processo de inclusão social, que deve ser compreendido como um processo no qual não apenas a pessoa com deficiência deve se adaptar, mas também a sociedade (DE CARLO; BARTALOTTI, 2001).

$\mathrm{O}$ processo de inclusão das pessoas com necessidades especiais na rede regular de ensino, em todos os seus graus, tem sido denominado educação inclusiva.

De acordo com as Diretrizes Nacionais para a Educação Especial na Educação Básica (BRASIL, 2001, p. 40):

O conceito de escola inclusiva implica uma nova postura da escola comum, que propóe no projeto pedagógico açóes que favoreçam a interação social e sua opção por práticas heterogêneas. A escola capacita seus professores, prepara-se, organiza-se e adapta-se para oferecer educação de qualidade para todos, inclusive para os educandos que apresentam necessidades especiais. Inclusão, portanto, não significa matricular todos os educandos com necessidades educacionais especiais na classe comum, ignorando suas necessidades específicas, mas significa dar ao professor e à escola o suporte necessário à sua ação pedagógica.

Desse modo, a inclusão escolar existe para ampliar $o$ acesso das pessoas com necessidades especiais nas classes comuns e mostrar que as pessoas podem aprender juntas, embora tendo objetivos e processos diferentes. Assim, a educação inclusiva alcança todos os níveis de ensino, desde a educação infantil ao ensino superior. Essa modalidade de educação é considerada como um conjunto de recursos educacionais e de estratégias de apoio, oferecendo diferentes alternativas de atendimento.

As ações tomadas pela Secretaria de Educação Especial (SEESP), órgão do Ministério da Educação (MEC) responsável pela educação da pessoa com necessidades especiais, vêm revelando um interessante movimento em respeito aos direitos desses cidadãos, desenvolvendo açôes em áreas estratégicas que visam contribuir com a inclusão de todos no sistema educacional, como adaptações curriculares, formação de recursos humanos e organização de serviços de apoio especializado.

Os dados do Censo Escolar de 2005 (MEC/ INEP) registram que a participação do atendimento inclusivo cresceu no Brasil, passando dos 24,7 em 2002 para $41 \%$ em 2005 , o que representa um aumento de $73 \%$ em estabelecimentos públicos com educação especial, entre 2002 e 2005. Cabe destacar, ainda, o aumento de $40,4 \%$, no período entre 2004 e 2005, de matriculas de crianças com necessidades especiais na rede pública de educação infantil regular (BRASIL, 2008).

A atual Política Nacional de Educação Especial na Perspectiva da Educação Inclusiva (BRASIL, 2008, p. 14) tem por um de seus principais objetivos

[...] assegurar a inclusão escolar de alunos com deficiência, transtornos globais do desenvolvimento e altas habilidades/ superdotação, orientando os sistemas de ensino para garantir entre eles a articulação intersetorial na implementação das políticas públicas.

De acordo com Werneck (2001), a maioria das crianças em idade pré-escolar descobre ser capaz de atos solidários e cooperativos, tornando-se mais compreensiva, tolerante e confiante nas relaçóes interpessoais. A criança demonstra, de forma espontânea, a colaboração com colegas, especialmente com aqueles que apresentam deficiências. Assim sendo, a autora afirma que o processo de inclusão traz benefícios tanto para o deficiente como para a criança comum.

Ao se pensar na qualidade da educação infantil, deve-se também considerar que as atividades oferecidas às crianças têm papel fundamental no desenvolvimento de habilidades psicomotoras, perceptocognitivas e da autonomia.

Assim, a inclusão da criança com necessidades especiais na escola também é objetivo da Terapia Ocupacional, na medida em que o ambiente escolar permite à criança a experimentação de uma diversidade maior de atividades, as quais promovem o desenvolvimento global da criança, o aprimoramento de habilidades e capacidades, a superação de dificuldades e a descoberta de que é parte integrante e atuante de uma sociedade. $\mathrm{O}$ ambiente escolar também possibilita à criança sem deficiência aprender que o ambiente social é constituído de pessoas singulares, com características diversas que devem ser respeitadas.

Entretanto, no Brasil a atuação da Terapia Ocupacional na escola regular é ainda recente, tanto no que se refere à prática profissional quanto à pesquisa. Cabe destacar que é essencial que haja a consolidação da atuação do Terapeuta Ocupacional na educação regular, estabelecendo efetiva interface entre as áreas da Saúde e da Educação, tão necessária para os processos de desenvolvimento e de inclusão da criança com necessidades especiais. 
Santos, Cardoso e Matsukura (2008) realizaram uma revisão literária acerca da Terapia Ocupacional e inclusão escolar, com destaque na escola. As autoras apontam que no ambiente escolar é possível promover o combate de atitudes segregacionistas e discriminatórias, não só com a participação dos educadores, mas considerando a necessidade de uma equipe com diversos profissionais, de modo a oferecer suporte aos alunos, família e comunidade. Entre esses profissionais, o Terapeuta Ocupacional se destaca pela sua capacidade de favorecer a funcionalidade das potencialidades de cada indivíduo, atuando como um facilitador da inclusão.

O estudo demonstrou três enfoques em relação ao papel do Terapeuta Ocupacional no espaço escolar: a viabilização do processo de inclusão através de assessoria ao professor e aos membros da comunidade; as possibilidades indiretas diante de necessidades $\mathrm{e}$ temores, da criança e da família, e o enfrentamento da mudança de paradigma médico para o educacional (SANTOS; CARDOSO; MATSUKURA, 2008).

A pesquisa de Cardoso e Matsukura (2008) mostra a caracterização das açóes e a realidade das práticas desenvolvidas por Terapeutas Ocupacionais no processo de inclusão escolar de crianças com necessidades educacionais especiais no Estado de São Paulo. Foram participantes desse estudo, 127 Terapeutas Ocupacionais, associados ao Conselho Regional de Fisioterapia e Terapia Ocupacional do Estado de São Paulo - CREFITO 3, que, em sua prática profissional, desenvolvem ou já desenvolveram ações voltadas para a inclusão escolar de crianças com necessidades educacionais especiais.

Os principais resultados encontrados pelas autoras indicaram que os Terapeutas Ocupacionais envolvidos com o processo de inclusão escolar realizam atividades nos dois contextos, clínico e escolar comum; realizam ainda atividades com a participação da família e de outros profissionais, e identificam a falta de preparo dos professores e da escola para o processo de inclusão escolar como os maiores obstáculos para a sua atuação.

Diante dos estudos mencionados, cabe ao Terapeuta Ocupacional contribuir para o encaminhamento da criança com necessidades especiais para a escola regular e atuar junto com a escola para oferecer atividades que efetivamente permitam o desenvolvimento, a aprendizagem e a inclusão da criança. Para isso, há a necessidade de um trabalho conjunto entre a Terapia Ocupacional e as instituiçóes de ensino regular.

Nesse sentido, o presente trabalho teve por objetivos específicos identificar e descrever as dificuldades, os benefícios e as sugestôes apontados pelos orientadores educacionais de educação infantil de um município da Baixada Santista quanto ao processo de inclusão escolar de crianças com necessidades educacionais especiais.

\section{Método}

\subsection{Participantes}

Inicialmente, o projeto previa a participação de professores da rede municipal de Educação Infantil, de uma cidade do litoral paulista. Entretanto, por solicitação do setor responsável pela autorização para a realização de pesquisas junto à Secretaria de Educação do município, os participantes deste estudo foram os orientadores educacionais. Considerou-se que os orientadores poderiam responder as questóes, levando em conta as condiçôes globais vividas pelos professores e pelas crianças com necessidades educacionais especiais, no processo de inclusão escolar. Assim, todos os orientadores das 20 Unidades de Educação Infantil da rede municipal foram convidados a participar.

\subsection{Procedimento}

Após autorização da Secretaria Municipal de Educação e aprovação do estudo pelo Comitê de Ética em Pesquisa da Universidade Federal de São Paulo, foi realizada uma reuniáo com todos os orientadores educacionais de Educação Infantil do município, na qual foi formalizado o convite, bem como apresentados os objetivos e as etapas da pesquisa, e entregues os Termos de Consentimento Livre e Esclarecido.

$\mathrm{O}$ instrumento de coleta de dados utilizado foi um questionário com questôes semiabertas. $\mathrm{O}$ questionário teve como foco identificar dificuldades apontadas pelos orientadores educacionais quanto ao processo de educaçáo inclusiva e as sugestôes de açôes que poderiam subsidiar práticas relacionadas às adaptaçóes de materiais e espaços físicos, às atividades educacionais, à formaçáo continuada e aos serviços de apoio especializado.

Os questionários foram entregues aos orientadores educacionais no mês de maio de 2007, com um acordo pré-estabelecido para devolução no mês de julho de 2007. Ao todo, 16 questionários foram respondidos e recolhidos. Entretanto, um dos questionários foi excluído da amostra por estar incompleto. Assim, o número total da amostra foi de 15 questionários. Esse número de respostas corresponde a $75 \%$ do 
total de orientadores educacionais das Unidades Municipais de Educação Infantil.

\section{Resultados}

\subsection{Caracterização dos participantes}

Todos os participantes são do gênero feminino. A idade delas variou entre 28 e 64 anos. Com relação às escolas nas quais trabalham, aproximadamente (93\%) das orientadoras atuam apenas na Educação Infantil. Somente uma das participantes (7\%) afirmou trabalhar como orientadora educacional em uma escola de Educaçáo Infantil e Fundamental.

O tempo de trabalho das orientadoras na área da educação é, na maioria (80\%), de mais de dez anos de experiência. Na questão sobre a formação acadêmica dos participantes, o questionário visou identificar as formaçóes complementares e continuadas dos orientadores educacionais, já que todos são graduados em Pedagogia. Cerca de 53\% das orientadoras educacionais possuem especialização, $29 \%$ possuem apenas a graduação em Pedagogia e 18\% possuem uma segunda graduação.

Foi questionado às orientadoras educacionais se já haviam trabalhado ou trabalhavam, no momento da pesquisa, com crianças com necessidades educacionais especiais. Constatou-se que a maioria $(80 \%)$ das orientadoras educacionais possuía alguma experiência com essa clientela.

Também foi investigado se as orientadoras educacionais já haviam feito algum curso ou algum outro tipo de formação que lhes auxiliasse a trabalhar em educação inclusiva ou com crianças com necessidades educacionais especiais. O resultado foi que a maioria $(60 \%)$ não possui qualquer formação específica; já 33\% das orientadoras mencionaram possuir alguma formaçáo que visou auxiliar no assunto. Foram citados: curso de Libras (linguagem de sinais), palestras, workshop e capacitação para orientadores educacionais na educação inclusiva, sendo esta última oferecida pela própria Secretaria da Educação.

\section{2 $\mathrm{O}$ que pensam as orientadoras educacionais}

Serão apresentadas e discutidas as quatro questóes específicas do questionário, relacionadas aos benefícios, dificuldades e sugestôes das orientadoras educacionais quanto ao processo de educação inclusiva de crianças com necessidades educacionais especiais (NEE) e aos seus professores.

Questáo 1. Enumere até 5 dificuldades que a criança com necessidades educacionais especiais pode encontrar na escola.

Nessa questão, foi obtido um total de 68 enumeraçóes relativas às dificuldades que a criança com NEE pode encontrar na escola, de acordo com os orientadores educacionais. Os resultados foram agrupados por semelhanças, que compuseram seis categorias distintas: Ambiente Escolar, Socialização, Adaptação e Comportamento da Criança, Atenção Especializada, Capacitação dos Profissionais e Outros. A Tabela 1 apresenta as Categorias relativas à primeira questão.

Dentre as categorias, a mais frequente foi Ambiente Escolar, com $45 \%$ das citaçôes. Pelo grande número do total de respostas e por representar diferentes aspectos do Ambiente Escolar, estes foram divididos em subcategorias: Mobiliário e Materiais, Espaço Fisico, Salas Numerosas, Falta de Professor Auxiliar elou Especializado.

Em seguida, com $16 \%$, encontra-se a categoria Socialização; nesta, podem-se exemplificar citações, como "sociabilidade", "integraçáo social", "preconceito", "aceitação de colegas" algumas vezes "aceitação do professor", entre outras.

Adaptação e Comportamento da Criança aparece com $15 \%$ do total dos resultados. Aspectos como "adaptação na organização e rotina", "independência", "comportamento e relacionamento" e "coordenação motora" são exemplos das respostas que compuseram essa categoria.

Atenção Especializada é a categoria que ocupa o quarto lugar, com 12\%; algumas citaçóes são "ausência de profissionais especializados", "profissionais na área de suas dificuldades" e "falta de programa de atendimento".

Tabela 1. Distribuição da frequência das categorias relativas às dificuldades da criança com NEE.

\begin{tabular}{lcr}
\hline $\begin{array}{c}\text { Dificuldades criança NEE } \\
\text { na escola }\end{array}$ & & \\
\hline \multicolumn{1}{c}{ Categorias } & $\mathbf{n}^{\mathbf{0}}$ citações & $\%$ \\
\hline Ambiente escolar & 31 & 45 \\
Socialização & 11 & 16 \\
Adaptação e comportamento & 10 & 15 \\
da criança & & \\
Atenção especializada & 8 & 12 \\
Capacitação dos profissionais & 4 & 6 \\
Outros & 4 & 6 \\
Total & 68 & 100 \\
\hline
\end{tabular}


Verifica-se que as categorias Capacitação dos Profissionais e Outros aparecem com 6\% cada uma. Em Capacitação dos Profissionais, algumas das citaçóes são "capacitação para todos envolvidos no processo educacional" e "falta de preparo da comunidade escolar".

Em Outros, foram agrupadas as citaçóes que não se encaixaram em nenhuma das categorias discutidas, tais como "orientaçấo familiar", "métodos de avaliação não flexíveis" e "suporte ao professor".

Questáo 2. Enumere até 5 beneficios que a criança com necessidades educacionais especiais pode encontrar na escola.

A segunda questão refere-se aos benefícios que a criança com NEE pode encontrar na escola (Tabela 2). De acordo com as respostas dadas pelas orientadoras educacionais, foi possível encontrar quatro categorias: Socializaçâo, Desenvolvimento e Aprendizagem, Atenção e Apoio Especializado e Outros.

Do total de respostas dadas, as categorias Socialização e Desenvolvimento e Aprendizagem aparecem com $35 \%$ de frequência cada.

Cabe destacar que a categoria Socialização aparece tanto na questão referente às Dificuldades da Criança quanto em relação aos Benefícios da Criança na escola. Nesta última, surge com grande incidência e pode ser exemplificada com as seguintes citaçóes: "ampliação das relaçôes sociais", "interação social", "favorecer as outras crianças a conviver com a diversidade", "convívio fora do lar" e "respeito às diferenças.

Em Desenvolvimento e Aprendizagem, as orientadoras educacionais apresentaram uma ampla variedade de respostas: "desenvolvimento global", "desenvolvimento da área emocional", "autoestima”, "superação pessoal", "estimulação precoce", "aquisiçáo de conceitos e valores, higiene, limites, rotina" e "acesso a atividades e experiências diversas".

A categoria Atenção e Apoio Especializado aparece com $24 \%$ de frequência das respostas dadas. Esta categoria pode ser exemplificada com as seguintes citaçôes: "atendimento integrado (vários profissionais)", "encaminhamento a profissionais especializados", "ambiente acolhedor", "estímulo dirigido" e "sala de apoio às necessidades educacionais especiais".

Por fim, na categoria Outros, com 6\%, foi reunida uma variedade de respostas que não era possível agrupar nas demais categorias, como: "garantia de direitos", "oportunidade" e "lazer".

Questáo 3. Aponte até 5 dificuldades encontradas pelo professor que trabalha com a inclusão de crianças com necessidades educacionais especiais na escola.
Em relação à terceira questão, que discute as dificuldades encontradas pelo professor que trabalha com a inclusão de crianças com NEE, foram descritas quatro categorias: Ambiente Escolar; Capacitação; Apoio Especializado e Parcerias, e, por último, Familia. A Tabela 3 mostra os resultados percentuais relativos às categorias.

O maior índice de respostas dadas pelos orientadores educacionais a essa questáo estão relacionadas à categoria Ambiente Escolar (48\%). Por isso, essa categoria foi dividida em subcategorias: Salas de Aula Numerosas; Espaço Físico; Falta de Professor Auxiliar e Especializado; Materiais, e Acolhimento da Equipe.

Com 25\% de frequência nas respostas, Capacitação foi a categoria composta por um conjunto de citaçôes, como: "Falta de formação continuada", "Falta de cursos que auxiliem o trabalho do professor" e "Falta de capacitação ao professor".

A categoria Apoio Especializado e Parcerias segue com a frequência de $19 \%$ das respostas. "Falta de profissionais especializados para dar suporte", "Acompanhamento de profissionais, como fonoaudióloga, psicóloga etc." e "Falta de parcerias efetivas com a saúde" são alguns exemplos dessa categoria.

Por fim, a Família (8\%) também é apontada como uma dificuldade encontrada pelo professor no processo de educaçáo inclusiva, como, por exemplo:

Tabela 2. distribuição da frequência das categorias relativas aos benefícios da criança com NEE.

\begin{tabular}{lcr}
\hline Benefícios da criança na escola & & \\
\hline \multicolumn{1}{c}{ Categorias } & $\mathbf{n}^{\mathbf{0}}$ citações & $\%$ \\
\hline Socialização & 22 & 35 \\
Desenvolvimento e aprendizagem & 22 & 35 \\
Atenção e apoio especializado & 15 & 24 \\
Outros & 4 & 6 \\
Total & 63 & 100 \\
\hline
\end{tabular}

Tabela 3. Distribuição da frequência das categorias relativas às dificuldades do professor.

\begin{tabular}{lcr}
\hline \multicolumn{1}{c}{ Dificuldades do professor } & & \\
\hline \multicolumn{1}{c}{ Categorias } & $\mathbf{n}^{\mathbf{0}}$ citações & $\%$ \\
\hline Ambiente escolar & 34 & 48 \\
Capacitação & 18 & 25 \\
Apoio especializado e parcerias & 14 & 19 \\
Família & 6 & 8 \\
Total & 72 & 100 \\
\hline
\end{tabular}


"Barreiras familiares quanto à aceitação" e "Falta de interesse e/ou acompanhamento da família".

Questão 4. Aponte até 5 sugestôes de açōes oule intervençóes que possam auxiliar o professor que trabalha com a inclusão de crianças com necessidades educacionais especiais na escola.

Nas questôes anteriores, foram apontadas as dificuldades e os benefícios referentes às crianças com NEE e as dificuldades encontradas pelos professores. Nessa quarta questão, serão apresentadas as sugestóes feitas pelos orientadores educacionais que possam auxiliar o professor que trabalha com a inclusão escolar.

As categorias definidas nessa questão foram compatíveis com as dificuldades apontadas, quais sejam: Alteraçôes no Ambiente Escolar, Apoio Especializado e Parcerias, Capacitação Profissional, Outros e Família. A Tabela 4 demonstra as Categorias relativas às sugestóes dos orientadores educacionais.

Alteraçōes no Ambiente Escolar é a categoria de maior frequência (47\%), ao mesmo tempo em que a mesma surge em primeiro lugar em Dificuldades da Criança e em Dificuldades do Professor. Essa categoria será discutida posteriormente.

Com 28\% de frequência, aparece Apoio Especializado e Parcerias. Algumas sugestôes são: "Parceria com profissionais na área de saúde", "Suporte de profissional especializado" e "Atuação do professor da sala de apoio às necessidades educacionais especiais em conjunto com o professor da classe".

Capacitaçâo Profissional aparece em terceiro lugar com 15\%, completando o item Apoio Especializado e Parcerias; neste, sugerem-se intervençóes de profissionais que atuem junto ao professor; já em Capacitação Profissional, uma intervenção que atue diretamente com o professor, como: "Capacitação contínua aos professores", "Palestras e cursos" e "Capacitação aos profissionais e demais funcionários".

A categoria Outros aparece com 6\% de frequência e engloba sugestóes variadas, como: "Adoção de

Tabela 4. Distribuição da frequência das categorias relativas às sugestóes dos professores.

\begin{tabular}{lcc}
\hline \multicolumn{1}{c}{ Sugestões } & & \\
\hline \multicolumn{1}{c}{ Categorias } & $\mathbf{n}^{\text {0 }}$ citações & $\%$ \\
\hline Alterações no ambiente escolar & 32 & 47 \\
Apoio especializado e parcerias & 19 & 28 \\
Capacitação profissional & 10 & 15 \\
Outros & 4 & 6 \\
Família & 3 & 4 \\
Total & 68 & 100 \\
\hline
\end{tabular}

práticas que proporcionarem ajuda na solução de problemas e dificuldades" e "Qualidade".

A Família, com 4\%, é o item de menor índice de sugestóes, assim como o de menor frequência em Dificuldades do Professor. As sugestôes foram: "Orientação para trabalhar com a família", "Maior envolvimento da família" e "Conscientização por parte dos pais com relaçáo às dificuldades da criança”.

Como indicado anteriormente, a categoria Alteraçóes no Ambiente Escolar, por apresentar alta percentagem de respostas e por estar relacionada a diferentes aspectos da mesma temática, foi dividida em subcategorias: Professores Auxiliares e de Apoio, Mobiliário e Materiais, Espaço Físico e Salas Menos Numerosas. A frequência na qual essas subcategorias aparecem estáo apresentadas na Tabela 5.

Professores Auxiliares e de Apoio é a subcategoria de maior incidência, com 34\%; Mobiliário e Materiais, com 25\%; Espaço Físico aparece com a frequência de $22 \%$, e Salas Menos Numerosas, com 19\%.

"Auxiliar fixo nas salas de aula", "Professor auxiliar de inclusão sem desvio de função" e "Professor de educação especial nas escolas" são algumas sugestôes da subcategoria Professores Auxiliares e de Apoio.

No quesito Mobiliário e Materiais, encontram-se: "Mobiliário adequado", "Planejamento e adaptaçóes de mobiliários", "Materiais pedagógicos adequados" e "Recursos materiais".

No âmbito Espaço Físico, "Sala de apoio", "Espaço adequado para atendimento", "Adaptação de ambientes" e "Implantação de salas de apoio" são algumas das sugestóes.

Para finalizar, Salas Menos Numerosas demonstra a necessidade de redução do número de alunos por sala de aula para a melhora no processo de ensino-aprendizagem.

\section{Discussão}

O presente estudo apresentou resultados sobre o processo de inclusão escolar em unidades municipais

Tabela 5. Distribuição da frequência das subcategorias relativas às alteraçôes no ambiente escolar.

\begin{tabular}{lcc}
\hline \multicolumn{1}{c}{ Alterações no ambiente escolar } & & \\
\hline \multicolumn{1}{c}{ Subcategorias } & $\mathbf{n}^{\mathbf{0}}$ citações & $\%$ \\
\hline Professores auxiliares e de apoio & 11 & 34 \\
Mobiliário e materiais & 8 & 25 \\
Espaço físico & 7 & 22 \\
Salas menos numerosas & 6 & 19 \\
Total & 32 & 100 \\
\hline
\end{tabular}


de Educação Infantil, baseando-se na visão de orientadoras educacionais.

Pode-se perceber que há categorias semelhantes quanto às Dificuldades e aos Benefícios que os orientadores educacionais consideram que a criança com NEE pode encontrar na escola.

O fato de a categoria Socialização estar presente tanto como Benefícios quanto como Dificuldades da criança com NEE na escola, permite refletir sobre alguns aspectos. Apesar de o aspecto "preconceito" aparecer em algumas citaçóes como uma das dificuldades encontradas pelas crianças, foi identificado que há maior valorização, por parte dos educadores, da convivência entre crianças com NEE e as demais, como aspecto que favorece o desenvolvimento global de todas e promove a socialização entre elas. Essa convivência, desde as primeiras experiências na escola, pode contribuir para que haja uma diminuição de atitudes discriminatórias.

Referido como um dos Benefícios que a criança pode encontrar na escola, a Socialização aparece com o índice de $35 \%$ de frequência das respostas. De acordo com as teorias de Piaget e Vygotsky, tanto a aprendizagem quanto o desenvolvimento da criança ocorrem por intermédio da interação com o meio físico e social (DUARTE, 1998). Dessa forma, esses autores propōem que há benefícios não somente para a criança com NEE, mas também para aquelas crianças sem necessidades especiais, à medida que todos aprendem a conviver com as diferenças.

Com a mesma frequência nas respostas, a categoria Desenvolvimento e Aprendizagem complementa os Benefícios que a criança com NEE pode apresentar com a inclusão escolar; as orientadoras indicaram que a inclusão favorece o desenvolvimento global, melhora a autoestima, entre outros fatores que estão intimamente relacionados com a sociabilidade.

Atenção e Apoio Especializado também aparece (24\%) como categoria relacionada aos Benefícios relativos à criança com NEE no processo de inclusão escolar. Essa referência parece indicar a proposta desenvolvida em algumas escolas municipais, representada, por exemplo, pela implementação de salas de apoio às necessidades educacionais especiais e pela existência de um ambiente acolhedor.

Por outro lado, ao observar as Dificuldades que podem ser encontradas pelas crianças, a categoria Atenção Especializada aparece com menor incidência $(12 \%)$. Nesse caso, as respostas dadas apontaram para a falta de professores e profissionais especializados, como Psicólogos e Terapeutas Ocupacionais. Demonstra-se, dessa forma, que a comunidade escolar tem sentido necessidade de profissionais que possam contribuir com professores e funcionários da escola, além de proporcionar uma intervenção mais específica com a criança.

O trabalho de Cunha et al. (2008) teve por objetivo verificar as concepçóes de professores da rede pública municipal de Marília-SP sobre atuação da Terapia Ocupacional na educação. Conforme os resultados obtidos, não há conhecimento do papel do Terapeuta Ocupacional junto à escola regular; porém, os professores julgam importante a parceria entre saúde e educação. Além disso, os resultados mostram a ausência de Terapeutas Ocupacionais contratados na área da educação e a necessidade de divulgação do trabalho desses profissionais para que haja parceria, possibilitando a elaboraçáo conjunta de planos de intervenção com as crianças com NEE.

O estudo de Lourenço e Cid (2010) realizou uma busca em publicaçóes na área sobre intervençôes da Terapia Ocupacional na Educação Infantil. Foram encontrados seis estudos que apresentavam formas de atuação da profissão nessa etapa da educação. As autoras concluíram que a Terapia Ocupacional está envolvida na promoção do desenvolvimento e do aprendizado de qualquer aluno, com ou sem deficiência. Essa promoção pode ocorrer por meio da participação na formação dos profissionais da comunidade escolar, da reestruturação de ambientes e da adaptação específica, assim como outras formas de intervenção que visem à melhoria do aprendizado das crianças.

As Dificuldades encontradas pelos professores e pelas crianças também se assemelham, uma vez que o desenvolvimento da criança não depende apenas do professor, mas também do ambiente escolar como um todo, desde a formaçáo dos profissionais até a estrutura física. Essas dificuldades formaram a categoria Ambiente Escolar, que aparecem em 45\% dos resultados relativos às dificuldades das crianças e em $48 \%$ para os professores.

O Ambiente Escolar diz respeito ao espaço físico e às relaçôes sociais existentes na escola, local onde as crianças realizam suas atividades; dentre estas, estão não só as atividades escolares, mas também as da vida diária, como alimentação, higiene e vestuário, e as atividades lúdicas e de socialização. Esse ambiente, consequentemente, tem grande influência no desenvolvimento global dessas crianças.

As respostas relacionadas ao Ambiente Escolar foram muito diversas e amplas. Com relação às dificuldades enfrentadas pelas crianças com NEE, a subcategoria de maior incidência foi Falta de Mobiliário e Materiais. Esse fator confirma que as crianças com NEE muitas vezes precisam de 
instrumentos e materiais específicos para sua necessidade e esse fator pode ser avaliado e adaptado por terapeutas ocupacionais, como aponta Munguba (2007).

Diversamente, a maior dificuldade encontrada pelo professor quanto ao Ambiente Escolar diz respeito ao grande número de alunos em sala de aula. Tal aspecto parece demonstrar como um fator não diretamente relacionado à criança com NEE pode interferir no seu processo de ensino-aprendizagem e de inclusão escolar.

A segunda maior dificuldade relativa ao Ambiente Escolar apontada tanto para crianças como para os professores é o Espaço Físico, que demonstra falta de adequação arquitetônica, o que pode dificultar na inclusão de alguma criança com NEE, assim como a acessibilidade em geral.

Nesse aspecto, o estudo de Paula e Baleotti (2011) traz uma contribuição sobre a atuação da Terapia Ocupacional em um estudo de caso de uma criança com deficiência física matriculada em uma escola regular e o desempenho de aprendizado dessa criança avaliado pela professora. Reforça-se que o Terapeuta Ocupacional pode intervir no ambiente escolar com adaptaçóes de mobiliários e recursos pedagógicos, apontando a importância da orientação ao professor quanto ao posicionamento do aluno e às mudanças posturais. Foi demonstrado que as maiores dificuldades do aluno estavam relacionadas ao ambiente escolar e à falta de recursos adaptados. Nesse sentido, a parceria entre a Terapeuta Ocupacional e a professora foi fundamental para valorizar as capacidades de aprendizagem dessa criança.

A Falta de Professor Auxiliar e Especializado também aparece como uma dificuldade relativa ao ambiente escolar. Professores auxiliares são contratados especialmente para acompanhar o aluno com alguma NEE matriculado na rede regular de ensino e sua função é dar uma atenção a esse aluno em suas atividades escolares e de vida diária realizada na escola. Em alguns casos o professor auxiliar atende a mais de uma criança na sala. $\mathrm{O}$ número desses profissionais ainda é insuficiente, o que foi indicado como outro fator que pode dificultar a inclusão escolar, tanto para a criança como para o professor.

A categoria Capacitação Profissional também apareceu como Dificuldades tanto da criança quanto do professor no processo de inclusáo escolar, e do mesmo modo nas Sugestóes.

De acordo com Munguba (2007), a formação continuada de professores é o percurso para o início de uma mudança no contexto educacional, visando à inclusão. Contudo, é necessário também sensibilizar as pessoas que ocupam cargos de direçáo para que a educação inclusiva se estabeleça como um processo de mudança. Desse modo, a autora ressalta que o Terapeuta Ocupacional, por se dedicar ao estudo do desenvolvimento humano e ao processo de aprendizagem e autonomia, encontra-se munido de arcabouço teórico e prático, da práxis, para contribuir para a desmistificação da abordagem ao indivíduo com NEE.

Segundo Sadalla (1997), a formaçáo é um processo constante que vai além da realização de cursos, na medida em que deve ser compreendido como um processo contínuo, no qual o professor necessita de auxílio para refletir sobre sua prática em sala de aula. Nesse sentido, o Terapeuta Ocupacional também pode contribuir para dar esse apoio ao professor.

Nessa perspectiva, o trabalho de Barba (2008) defende a atuação de terapeutas ocupacionais no processo de inclusão escolar de alunos com NEE, ao descrever uma experiência de atuaçáo dentro de um modelo de Consultoria Colaborativa junto a educadores de uma rede de ensino regular municipal, confirmando a importância do trabalho intersetorial. Esse trabalho foi realizado junto a professores de 14 escolas (Ensino Infantil e Fundamental) de uma cidade do interior de Sáo Paulo, consistindo de um levantamento de alunos com NEE e na oferta de suporte baseado em consultoria colaborativa. Nesse processo, foram realizados encaminhamentos a várias especialidades, apresentadas sugestóes à Secretaria Municipal de Educação e iniciado o suporte itinerante baseado na consultoria colaborativa aos educadores envolvidos, constituindo-se de estudos de caso, cursos teórico-práticos, discussão sobre flexibilizaçóes curriculares e elaboração de Plano Individualizado de Ensino. Os resultados foram considerados positivos, já que os educadores se tornaram mais reflexivos e permitiram abrir possibilidades de replanejar.

As Sugestôes dadas pelos orientadores educacionais na última questão são condizentes com as dificuldades apontadas. As Sugestóes de maior incidência dizem respeito às alteraçóes no ambiente escolar. Como referido anteriormente, o ambiente escolar tem grande influência na vida diária dos alunos e também dos professores. Um ambiente adaptado, com mobiliários e materiais adequados, a presença de professores auxiliares e especializados, e o menor número de alunos em sala são fatores que possivelmente facilitariam a inclusão escolar de crianças com NEE.

Aspectos como adaptação e adequação de mobiliários e materiais podem ser solucionados por profissionais capacitados em tecnologia assistiva, como é o caso de Terapeutas Ocupacionais. 
A tecnologia assistiva consiste em um conjunto de recursos e serviços que contribuem para proporcionar ou ampliar habilidades funcionais de pessoas com deficiência e, consequentemente, promover a autonomia e a inclusão (BERSCH, 2005).

Apoio Especializado e Parcerias constituiu a segunda categoria de Sugestóes de maior incidência e parece representar a necessidade de serviços especializados que atendam náo só a criança com NEE, mas que trabalhem em parceria com toda comunidade escolar, como previsto nas Diretrizes Nacionais para a Educação Especial na Educação Básica (BRASIL, 2001).

Essas diretrizes indicam que tais serviços deverão ser realizados mediante a atuação de diferentes profissionais das áreas de Educação e da Saúde. Ressalta-se, ainda, a necessidade de uma rede de apoio intersetorial entre as áreas da Saúde, da Assistência Social e do Trabalho.

Os resultados encontrados por Cardoso e Matsukura (2008) indicaram que os Terapeutas Ocupacionais envolvidos com o processo de inclusão escolar realizam atividades nos dois contextos, clínico e escolar comum; com a participação da família e de outros profissionais, identificam a falta de preparo dos professores e da escola para o processo de inclusão escolar como os maiores obstáculos para a sua atuação.

As citaçôes relativas à Família apareceram com pouca incidência, tanto nas Dificuldades encontradas pelos professores quanto na Sugestão.

De acordo com Costabile e Brunello (2005), a família é grande colaboradora para o desenvolvimento da criança e caminha em conjunto com a escola. Por ser a maior observadora das limitaçôes e habilidades que a criança tem no processo de inclusão, é fundamental um diálogo entre a escola e os familiares. Entretanto, ressaltam que em ocasiôes nas quais a família encontra-se pouco envolvida ou ausente no processo de inclusão, a escola poderia auxiliá-la na conscientização da NEE da criança, pois algumas famílias não conseguem aceitar a deficiência.

O Terapeuta Ocupacional pode contribuir para tal aproximação com o objetivo de propor melhora no desenvolvimento da criança não apenas relacionado às necessidades educacionais especiais, mas também à vida diária do aluno fora da escola.

\section{Considerações finais}

Os resultados desta pesquisa permitiram verificar alguns fatores relacionados ao processo de inclusão escolar de unidades municipais de Educação Infantil de uma cidade da Baixada Santista. Os dados relativos às dificuldades encontradas pelas crianças com necessidades educacionais especiais, assim como as apontadas pelos professores, indicam que tais dificuldades parecem não estar diretamente relacionadas às deficiências das crianças matriculadas nas escolas ou de seus quadros clínicos, mas sim a todo o contexto educacional.

Nesse sentido, o presente trabalho contribuiu para fornecer subsídios para a elaboração de diversas açôes que visam à melhoria na atenção especializada à criança com necessidades educacionais especiais, no processo de inclusão escolar. Está de acordo com Munguba (2007), quando afirma que o Terapeuta Ocupacional deve começar a se aproximar mais do universo de educaçáo, para posteriormente se integrar neste e atuar de modo efetivo para a inclusão escolar.

A atuação do Terapeuta Ocupacional em escolas regulares ainda é uma prática de pouca incidência no Brasil; porém, sua participação na comunidade escolar pode auxiliar na adaptaçáo do ambiente escolar e de materiais, na orientação e na sensibilização dos atores sociais envolvidos com a criança com NEE (família, professores, funcionários, colegas de sala), na avaliação da estrutura escolar, no acompanhamento do aluno encaminhado da escola especial para a regular e na avaliaçáo periódica do desenvolvimento da criança, entre outras intervençóes que dependem de fatores singulares de cada situação.

Cabe ainda ressaltar que os resultados obtidos neste estudo foram apresentados aos participantes do mesmo, em março de 2008, o que possibilitou discutir junto com a Secretaria de Educação sobre a elaboraçáo de novas propostas de trabalho da Terapia Ocupacional na educação inclusiva do município.

Longe de esgotar o assunto, o presente trabalho buscou contribuir não só para o levantamento dos aspectos relacionados ao processo de inclusão escolar do município, mas também, para a reflexão quanto às possibilidades de açóes integradas entre a Terapia Ocupacional e a educação inclusiva.

\section{Referências}

BARBA, P. C. S. D. Consultoria Colaborativa e Inclusão de Alunos com necessidades educacionais especiais: um relato da contribuição da Terapia Ocupacional. In: CONGRESSO BRASILEIRO DE EDUCAÇÃO ESPECIAL, 3., 2008, São Carlos. Anais... São Carlos, 2008.

BRASIL. Ministério da Educação - MEC. Secretaria de Educação Especial - SEE. Diretrizes nacionais para a educação especial na educação básica. Brasília: MEC; SEESP, 2001. 
BRASIL. Política Nacional Educação Especial na Perspectiva da Educação Inclusiva. Brasília: MEC, 2008.

BERSCH, R. Introdução à Tecnologia Assistiva. Porto Alegre: Artmed, 2005.

CARDOSO, P. T.; MATSUKURA, T. S. Inclusão Escolar de Crianças com Necessidade Educacionais Especiais: Práticas e Perspectivas de Terapeutas Ocupacionais. In: CONGRESSO BRASILEIRO DE EDUCAÇÃO ESPECIAL, 3., 2008, São Carlos. Anais... São Carlos, 2008.

COSTABILE, C.; BRUNELLO, M. I. B. Repercussões da inclusão escolar sobre o cotidiano de crianças com deficiência: em estudo a partir do relato de famílias. Revista de Terapia Ocupacional da Universidade de São Paulo, v. 16, n. 3, p. 124-130, 2005.

CUNHA, V. D. S.; SILVA, A. C. A.; SILVA, J. A.; POKER, R. B. Concepção de Professores sobre a Atuação da Terapia Ocupacional nas Escolas da Rede Pública Municipal de Marília. In: CONGRESSO BRASILEIRO DE EDUCAÇÃO ESPECIAL, 3., 2008, São Carlos. Anais... São Carlos, 2008.

DE CARlO, M. M. R. P.; BARTAlOTTI, C. C. (Orgs.). Terapia ocupacional no Brasil. São Paulo: Plexus Editora, 2001.
DUARTE, N. Concepçóes afirmativas e negativas sobre o ato de ensinar. Caderno CEDES, vol. 19 n. 44, 1998

LORENÇO, G. F.; CID, M. F. B. Possibilidades de Ação do Terapeuta Ocupacional na Educaçáo Inclusiva. Cadernos de Terapia Ocupacional da UFSCar, v. 18, n. 2, p. 169-179, 2010.

MUNGUBA, M. C. Inclusão Escolar. In: CAVALCANTI, A.; GALVÃO, C. Terapia Ocupacional: fundamentos e prática. Rio de Janeiro: Guanabara Koogan, 2007.

PAULA, A. F. M.; BALEOTTI, L. R. Inclusão Escolar do Aluno com Deficiência Física: Contribuições da Terapia Ocupacional. Cadernos de Terapia Ocupacional da UFSCar, v. 19, n. 1, p. 53-69, 2011.

SADALLA, A. M. Com a palavra: suas crenças, suas ações. 1997. Tese (Doutorado em Educação)Universidade Estadual de Campinas, Campinas, 1997.

SANTOS, F. V.; CARDOSO, P. T.; MATSUKURA, T. S. Inclusão Escolar: Identificando a Produção de Conhecimento e Práticas de Terapeutas Ocupacionais. In: CONGRESSO BRASILEIRO DE EDUCAÇÃO ESPECIAL, 3., 2008, São Carlos. Anais... São Carlos, 2008.

WERNECK, C. Quando a educação é para todos? 2001. Disponível em: <http:/www.inclusao.com.br/index_. htm>. Acesso em: 19 out. 2008.

\section{Autores}

\section{Mariana Graziella Ide}

\section{Beatriz Tieko Yamamoto}

Terapeuta Ocupacional pela Universidade Federal de Sáo Paulo - UNIFESP, Campus Baixada Santista, Santos, SP, Brasil

\section{Carla Cilene Baptista da Silva}

Doutora em Psicologia Escolar e do Desenvolvimento Humano, Instituto de Psicologia - IP, Universidade de São Paulo -USP, Docente de Terapia Ocupacional da Universidade Federal de São Paulo - UNIFESP, Santos, SP, Brasil

\section{Contribuição dos Autores}

Carla Cilene Baptista da Silva: concepçáo do manuscrito, responsável pela pesquisa, revisão do manuscrito e orientadora. Mariana Graziella Ide e Beatriz Tieko Yamamoto: Redação do texto, pesquisa bibliográfica e colaboradora na coleta e análise dos dados

\section{Notas}

\footnotetext{
${ }^{1}$ As respostas dadas pelos participantes foram mantidas na íntegra e estão apresentados entre aspas.
} 